\title{
Metabolic profiling of early-lactation dairy cows using milk mid-infrared spectra
}

\author{
T. D. W. Luke, ${ }^{1,2}$ S. Rochfort, ${ }^{1,2}$ W. J. Wales, ${ }^{3}$ V. Bonfatti, ${ }^{4}$ L. Marett, ${ }^{3}$ and J. E. Pryce ${ }^{1,2 *}$ \\ ${ }^{1}$ Agriculture Victoria, AgriBio, Centre for AgriBioscience, Bundoora, Victoria 3083, Australia \\ ${ }^{2}$ School of Applied Systems Biology, La Trobe University, Bundoora, Victoria 3083, Australia \\ ${ }^{3}$ Department of Economic Development, Jobs, Transport and Resources, Ellinbank Centre, 1301 Hazeldean Rd., Ellinbank, Victoria, \\ 3820 Australia \\ ${ }^{4}$ Department of Comparative Biomedicine and Food Science, University of Padova, viale dell' Università 16 35020, Legnaro, PD, Italy
}

\section{ABSTRACT}

Metabolic disorders in early lactation have negative effects on dairy cow health and farm profitability. One method for monitoring the metabolic status of cows is metabolic profiling, which uses associations between the concentrations of several metabolites in serum and the presence of metabolic disorders. In this cross-sectional study, we investigated the use of midinfrared (MIR) spectroscopy of milk for predicting the concentrations of these metabolites in serum. Between July and October 2017, serum samples were taken from 773 early-lactation Holstein Friesian cows located on 4 farms in the Gippsland region of southeastern Victoria, Australia, on the same day as milk recording. The concentrations in sera of $\beta$-hydroxybutyrate (BHB), fatty acids, urea, $\mathrm{Ca}, \mathrm{Mg}$, albumin, and globulins were measured by a commercial diagnostic laboratory. Optimal concentration ranges for each of the 7 metabolites were obtained from the literature. Animals were classified as being either affected or unaffected with metabolic disturbances based on these ranges. Milk samples were analyzed by MIR spectroscopy. The relationships between serum metabolite concentrations and MIR spectra were investigated using partial least squares regression. Partial least squares discriminant analyses (PLS-DA) were used to classify animals as being affected or not affected with metabolic disorders. Calibration equations were constructed using data from a randomly selected subset of cows $(\mathrm{n}=579)$. Data from the remaining cows $(\mathrm{n}=194)$ were used for validation. The coefficient of determination $\left(R^{2}\right)$ of serum BHB, fatty acids, and urea predictions were $0.48,0.61$, and 0.90 , respectively. Predictions of $\mathrm{Ca}$, $\mathrm{Mg}$, albumin, and globulin concentrations were poor $\left(0.06 \leq \mathrm{R}^{2} \leq 0.17\right)$. The PLS-DA models could predict elevated fatty acid and urea concentrations with an ac-

Received May 23, 2018.

Accepted October 31, 2018.

*Corresponding author: jennie.pryce@ecodev.vic.gov.au curacy of approximately 77 and 94\%, respectively. A second independent validation data set was assembled in March 2018, comprising blood and milk samples taken from 105 autumn-calving cows of various breeds. The accuracies of BHB and fatty acid predictions were similar to those obtained using the first validation data set. The PLS-DA results were difficult to interpret due to the low prevalence of metabolic disorders in the data set. Our results demonstrate that MIR spectroscopy of milk shows promise for predicting the concentration of BHB, fatty acids, and urea in serum; however, more data are needed to improve prediction accuracies.

Key words: mid-infrared spectral prediction, metabolic profile, ketosis, energy balance

\section{INTRODUCTION}

Metabolic disorders in early lactation have significant negative effects on dairy cow health and welfare as well as farm profitability (Suthar et al., 2013; McArt et al., 2015). The most commonly described metabolic disorders are ketosis, hypocalcemia, and hypomagnesemia. Subclinical metabolic disorders, which are not associated with obvious clinical signs, are of particular interest due to their relatively high prevalence and significant effects on animal welfare and performance (Macrae et al., 2006; McArt et al., 2012; Suthar et al., 2013). Identification of subclinical disorders can also allow for timely management interventions to prevent the development of clinical disease.

One way of monitoring the metabolic health and nutritional status of dairy cows is serum metabolic profile testing, which employs well-established epidemiological associations between the concentrations of several metabolites in serum and the presence of both subclinical and clinical metabolic disorders (Payne et al., 1970; Ospina et al., 2010a). The metabolites evaluated in metabolic profile testing vary, but often include BHB and fatty acids as indicators of energy balance, albumin and BUN as indicators of protein status, globulins as an 
indicator of chronic inflammatory disease, and $\mathrm{Ca}$ and $\mathrm{Mg}$ as indicators of macromineral status (Whitaker, 2004; Anderson, 2009). Epidemiological studies have demonstrated that elevated concentrations of BHB and fatty acids in early lactation are associated with an increased risk of subsequent negative health events and reduced production (Ospina et al., 2010b; Chapinal et al., 2012; Sordillo and Raphael, 2013). Blood urea nitrogen concentration is of increasing interest, as it (1) gives an indication of RDP intake and the ratio of RDP to energy in the ration, and (2) has been demonstrated to be a useful indicator of an animal's nitrogen utilization efficiency and excretion (Kohn et al., 2005; Kume et al., 2008).

Critical concentration thresholds are used to define the optimum concentration range for of each metabolite employed in a metabolic profile test. Concentrations falling outside this range are associated with detrimental downstream health and production outcomes (Ospina et al., 2010b). Herd prevalence thresholds are similarly defined as the proportion of animals with metabolite concentrations outside the optimum range, above which detrimental herd-level health and production outcomes are seen (Ospina et al., 2010b; Chapinal et al., 2012). The aim of metabolic profiling is therefore not necessarily to identify individual sick animals, but to gain objective information on the nutritional status and metabolic health of a herd by estimating the prevalence of metabolic disorders.

Despite the advantages of metabolic profile testing, blood testing animals on a regular basis is invasive, logistically challenging, and costly. Given the ready availability of milk, its use as a biofluid to monitor the health and nutritional status of dairy cows has been widely investigated (Hamann and Krömker, 1997). In early lactation a milk fat-to-protein ratio of greater than 1.4 (Schcolnik, 2016) and 2.0 (Toni et al., 2011) have been described as indicators of negative energy balance and subclinical ketosis, respectively, and changes in milk fat-to-lactose and milk fat-to-protein ratios in early lactation have been suggested as early indicators of disease (Paudyal et al., 2016). Milk urea nitrogen is routinely used by nutritionists to monitor and optimize protein nutrition (Jonker et al., 2002; Nousiainen et al., 2004). More recently, mid-infrared (MIR) spectroscopy of milk has shown promise for assessing more complex animal health traits (Gengler et al., 2016). Several authors have demonstrated that MIR spectral data can be used to screen for subclinical ketosis through identification of ketone bodies in milk (de Roos et al., 2007; van Knegsel et al., 2010; Grelet et al., 2016) and to estimate energy balance in early lactation (McParland et al., 2011). Attempts have also been made to estimate the concentration of serum biomarkers of energy balance using milk MIR spectra (Gelé et al., 2015; Belay et al., 2017a; Pralle et al., 2018).

The aim of our study was to determine if MIR spectral data, obtained from routine milk recording in commercial dairy herds, could be used to predict the concentration of metabolites routinely employed in serum metabolic profiling, with sufficient accuracy to provide useful information on the metabolic health of early-lactation dairy cows. We also aimed to assess the robustness of MIR prediction equations by validating our results with data collected from a herd managed under a different production system and in a different season. If sufficiently accurate, milk MIR predictions of serum biomarkers may help to improve the health, welfare, and productivity dairy cattle by (1) allowing early identification of metabolic disease and (2) providing high throughput and cost-effective phenotypes for genetic evaluation of complex animal health traits.

\section{MATERIALS AND METHODS}

All procedures were conducted in accordance with the Australian Code of Practice for the Care and Use of Animals for Scientific Purposes (National Health and Medical Research Council, 2013). Approval to proceed was obtained from the Agricultural Research and Extension Animal Ethics Committee (Department of Economic Development, Jobs, Transport and Resources, Attwood, Victoria, Australia).

\section{Sample Collection}

Data Set 1. A single blood sample was taken from 773 spring-calving Holstein-Friesian cows in early lactation (between 5 and $49 \mathrm{DIM}$ ) on the same day as milk recording, between July and October 2017. The cows were located on 4 farms (farms A, B, C, and D) in the Gippsland region of southeastern Australia. All 4 farms operated a seasonal calving system, with the majority of cows calving in a short period of time to align the peak nutritional demands of the herd with maximal pasture availability. The farms implemented a feeding system reliant on grazed pasture plus other forages, with more than $1 \mathrm{t}$ of a cereal grain per cow per year fed in the parlor at milking time. Two of the farms (farms C and D) operated rotary milking platforms, which allowed blood samples to be collected during milking. Samples were taken immediately after milking on the other 2 farms. Samples were collected after the morning milking on farm A, after the afternoon milking on farm B, and during the afternoon milking on farms $\mathrm{C}$ and D.

Blood was collected from the coccygeal vein into 10-mL serum clot activator vacutainer tubes (Becton 
Dickinson, Franklin Lakes, NJ). Samples were allowed to clot for a minimum of $1 \mathrm{~h}$ at room temperature before centrifugation at $1,200 \times g$ for $10 \mathrm{~min}$ at $18^{\circ} \mathrm{C}$. All samples were processed within $6 \mathrm{~h}$ of collection. Serum samples were refrigerated at $4^{\circ} \mathrm{C}$ then transported on ice to Regional Laboratory Services (Benalla, Victoria, Australia) within $24 \mathrm{~h}$ of collection. Samples were analyzed for concentrations of BHB, fatty acids, BUN, total $\mathrm{Ca}, \mathrm{Mg}$, total protein, and albumin using a Kone 20 XT clinical chemistry analyzer (Thermo Fisher Scientific, Waltham, MA), with reagents supplied by Randox Laboratories (Crumlin, UK) for fatty acids, BUN, $\mathrm{Ca}$, and $\mathrm{Mg}$, and Regional Laboratory Services (Benalla, Victoria, Australia) for BHB, albumin, and total protein. Globulin concentrations were calculated as total protein concentration minus albumin concentration. Milk samples were collected as part of routine milk recording by the Herd Improvement Co-Operative Australia (Maffra, Victoria, Australia). Samples were preserved with SomaGlo (proprietary formulation, Bentley Instruments, Chaska, MN) and analyzed fresh using MIR spectroscopy (Bentley Instruments NexGen FTS Combi) by TasHerd Pty Ltd. (Hadspen, Tasmania, Australia).

Farm E Independent Validation Data Set. To test the robustness of MIR-prediction equations, a second independent validation data set was assembled in March 2018. This data set comprised a further 105 blood and milk samples taken from cows of different breeds, managed under a different production system, and calving in a different season (autumn as opposed to spring). The farm was located in the Gippsland region of southeastern Australia, and the herd consisted of Jersey, Australian Red, Holstein-Friesian, and crossbred cows. Cows were fed a diet consisting of grazed chicory, a ration of pasture silage, cottonseed and canola meal, and a wheat-barley grain mix fed in the parlor at milking time. Blood samples were collected immediately after the afternoon milking. Blood and milk samples were analyzed using the same protocols described for data set 1 .

\section{Statistical Analysis}

Effect of Week of Lactation, Parity and Farm on Metabolite Concentrations. Fixed effects models were constructed to evaluate the effect of weeks in milk, parity, and farm, on the concentrations of each metabolite:

$$
y_{i j k l}=\mu+W I M_{i}+P_{j}+F_{k}+e_{i j k l}
$$

where $y$ is the metabolite concentration (BHB, fatty acids, $\mathrm{Ca}, \mathrm{Mg}$, urea, albumin, and globulin), $\mu$ is the mean, WIM is weeks in milk (from 1 to 8 ), $P$ is parity (primiparous vs. multiparous), $F$ is the effect of farm, and $e$ is the random error term. Phenotypic correlations between metabolite concentrations were investigated by calculating the Pearson correlations between the residuals of each model.

Optimum metabolite concentration ranges were defined based on thresholds obtained from the literature and are shown in Table 1. Each metabolite concentration for every animal was classified as being either within or outside the defined optimum range, thus converting each continuous metabolite concentration variable into a binary trait. The prevalence of each metabolic disorder was then calculated as the percentage of animals that had a metabolite concentration outside the optimum range.

MIR Predictions. All MIR spectral data analysis was performed with Matlab R2017a (MathWorks, Natick, MA) utilizing the PLS Toolbox (Eigenvector Research, Manson, WA).

Preprocessing of Metabolite Concentrations. The distributions of serum metabolite concentrations were visually assessed for normality using frequency histograms. The fatty acid and BHB concentration distributions were both skewed, with lower values over-represented; this type of distribution leads to decreased accuracy in predicting high values in partial least squares (PLS) regression (Grelet et al., 2016), so a logarithmic (10) transformation was applied to BHB

Table 1. Upper and lower concentration thresholds for serum metabolites used for metabolic profile analyses

\begin{tabular}{|c|c|c|c|}
\hline \multirow[b]{2}{*}{ Metabolite } & \multirow[b]{2}{*}{ Reference } & \multicolumn{2}{|c|}{ Optimum concentration of serum metabolites } \\
\hline & & Lower threshold & Upper threshold \\
\hline Fatty acids $(\mathrm{mmol} / \mathrm{L})$ & Ospina et al., 2010a & - & 0.7 \\
\hline $\mathrm{Ca}(\mathrm{mmol} / \mathrm{L})$ & DeGaris and Lean, 2008 & 2.0 & - \\
\hline $\mathrm{Mg}(\mathrm{mmol} / \mathrm{L})$ & Anderson, 2009 & 0.62 & - \\
\hline Urea $(\mathrm{mmol} / \mathrm{L})$ & Butler et al., 1996; Macrae et al., 2006 & 1.7 & 6.78 \\
\hline
\end{tabular}


concentrations and a square root transformation was applied to fatty acid concentrations (Figure 1).

Preprocessing of Spectra. The MIR spectra were expressed in absorbance, with 899 spectral points between 649 and $3,998 \mathrm{~cm}^{-1}$. Preliminary analysis of the spectral data was conducted using principal component analysis. No outliers were identified in the data set. Spectral regions associated with the $\mathrm{O}-\mathrm{H}$ bending and stretching regions of water were excluded (Afseth et al., 2010; Belay et al., 2017a). This left 538 spectral wavelengths between 928 and 1,596 as well as 1,693 and $3,025 \mathrm{~cm}^{-1}$ for the subsequent chemometric analysis. The MIR spectra were preprocessed with Savitzky-Golay second derivative transformation and smoothing, removal, of linear trend and autoscaling (Eigenvector, 2018).

Calibration and Validation. The relationships between blood metabolite concentrations and milk MIR spectra were investigated using PLS regression analysis. Partial least squares discriminant analysis (PLS-DA) was used to classify animals as being either affected or not affected with a metabolic disorder based on the aforementioned binary metabolic profile classifications.

Calibration equations were constructed using a randomly allocated subset of data set 1 , which consisted

a)

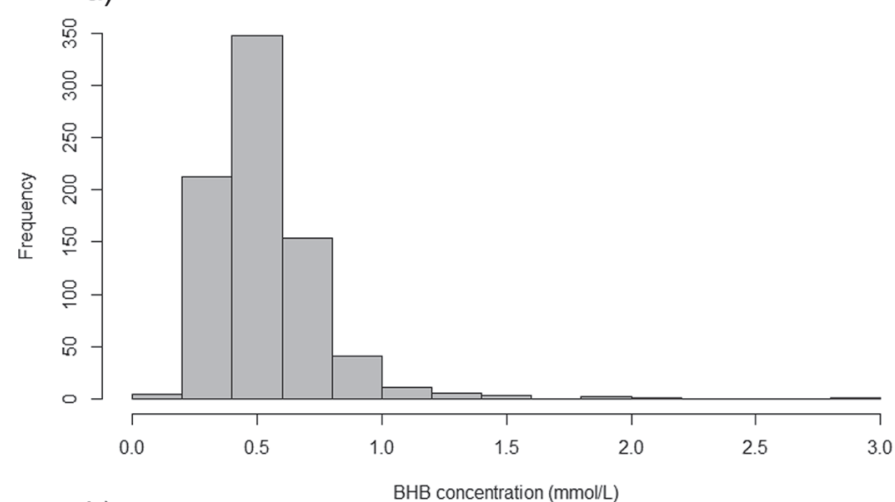

b)

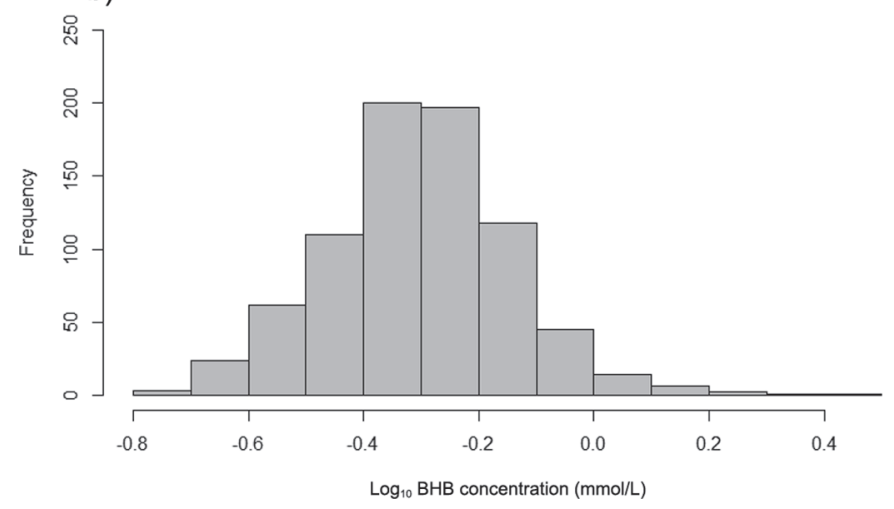

of serum metabolic profile results and MIR spectral data from 579 animals (hereafter referred to as the calibration data set). These calibration equations were used for all subsequent analyses. The data from the remaining 194 animals from data set 1 were used for external validation (hereafter referred to as the random validation data set). The calibration and random validation data sets were designed to have a representative number of samples from each farm and parity category (primiparous or multiparous) and were balanced for DIM.

The number of latent variables ( $\mathbf{L V})$ included in each calibration model was based on maximizing the percentage of variance captured while minimizing the root mean square error of cross-validation $\left(\mathbf{R M S E}_{\mathbf{C V}}\right)$. The optimum number of LV was determined for each calibration model by examining a plot of $\mathrm{RMSE}_{\mathrm{CV}}$ as a function of number of LV.

Each calibration model was assessed for over-fitting using a permutation test with 50 iterations. Permutation testing of regression models involved randomly reordering the $y$ block, and nominally assigning an incorrect $y$ value to each vector of $x$ values (Eigenvector, 2018). For example, with our data this involved randomly assigning an incorrect serum metabolite concentration

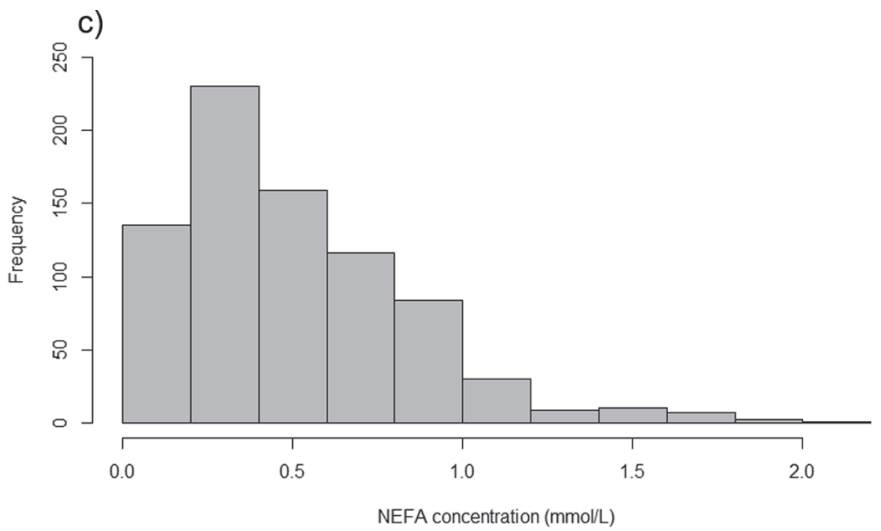

d)

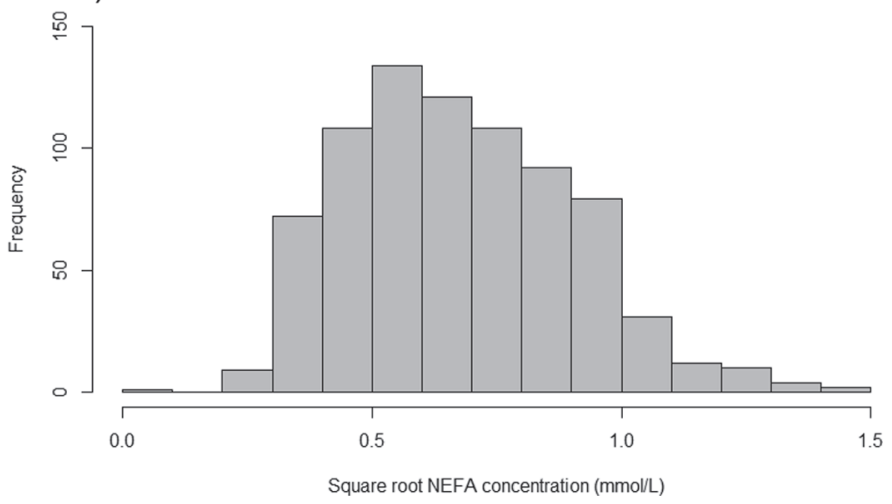

Figure 1. (a) Frequency distribution of untransformed serum BHB concentrations, (b) serum BHB concentrations following Log 10 transformation, (c) untransformed serum fatty acids, and (d) serum fatty acid concentrations following square root transformation. 
Table 2. Number of cows with metabolic profiles and milk mid-infrared spectral data by farm and by data set, including stage of lactation (DIM means and ranges) and percentage of animals in their first lactation

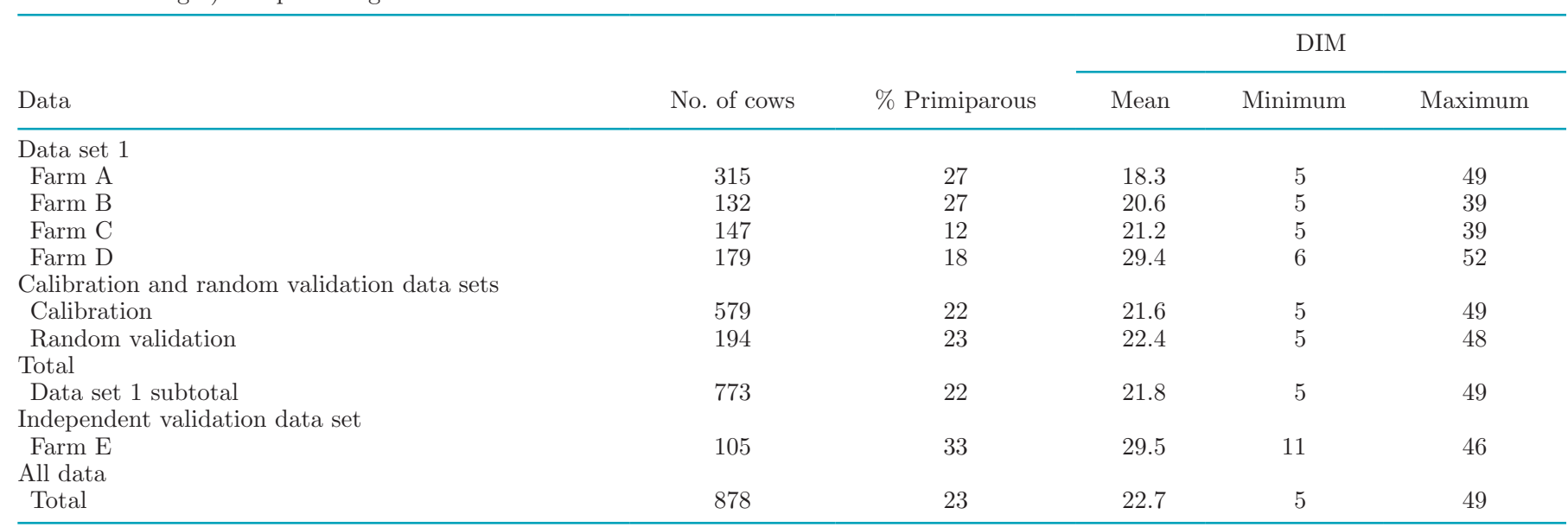

(the $y$ value) to an MIR absorbance spectrum (a vector within the $x$ block). The model was then rerun using the original parameters, but with the randomly aligned data. This process was repeated 50 times and the results obtained using the randomly assorted data were compared with the results of the correctly aligned data. A Wilcoxon signed-rank test was then used to assess the probability that the original model was significantly different from those built using the randomly assorted data (Eigenvector, 2018). A $P$-value of less than 0.05 indicated that the original model was significantly different to the random models and was therefore unlikely to be over-fitted.

Validation was performed in 3 ways. (1) Cross-validation was performed on the calibration data set $(\mathrm{n}=$ 579) using a venetian blinds method (which splits the data into 20 subsets and performs cross-validation on 2 samples per subset). (2) External validation was carried out using the random external validation data set $(\mathrm{n}=194)$ and (3) external validation was done using the farm $\mathrm{E}$ independent validation data set $(\mathrm{n}=105)$.

The accuracy of PLS models was assessed using the coefficient of determination $\left(\mathbf{R}^{2}\right)$ and the root mean square error (RMSE). The accuracy of PLS-DA models was assessed by calculating the sensitivity, specificity, classification error ( $\mathbf{C E})$, and the area under the receiver operator curve (AUC).

\section{RESULTS}

\section{Descriptive Statistics}

Details of the animals included in the analysis are summarized in Table 2. Of the 878 animals included in the analysis, $36 \%$ (315 cows) were from farm A. The remaining 563 animals were evenly distributed between the remaining 4 farms. Of the animals sampled, $78 \%$ (682 cows) were in the first $30 \mathrm{~d}$ of lactation, which is the period of highest risk for development of metabolic disorders (LeBlanc et al., 2006). The overall percentage of primiparous animals in the data set was $23 \%$, with a range of approximately 12 to $33 \%$ between farms.

The identity of the farm had a significant effect $(P$ $<0.05)$ on the concentration of all metabolites. The number of weeks after a cow had calved had a significant effect on BHB, fatty acid, BUN, magnesium, and globulin concentrations. Parity had a significant effect on the concentration of all metabolites except those of fatty acids and albumin.

Descriptive statistics for the concentrations of each metabolite measured are summarized in Table 3. The distribution of metabolite concentrations in the calibration and random validation data sets were very similar; however, we found considerable differences in the distributions of fatty acid and urea concentrations between the calibration data set and the farm E independent validation data set.

Corrected mean metabolite concentrations for each 7-d period are shown in Figure 2. Both BHB and fatty acid concentrations were highest immediately postcalving and decreased over time. The concentrations of the remaining 5 metabolites exhibited an increasing trend over the 7-wk period. Calcium, urea, and albumin concentrations peaked at wk 7 postcalving, and globulin concentrations peaked at wk 5 postcalving. Magnesium concentrations peaked at wk 3 postcalving, then plateaued.

The number and percentages of animals with metabolite concentrations outside optimal ranges are shown in Table 4. A total of $56 \%$ (489 cows) had 1 or more metabolites outside optimal ranges. Aberrant protein concentrations were the most prevalent 
disorder observed, with 39\% (339 cows) having either elevated serum urea $(31 \%)$ or globulin $(3 \%)$ concentrations or low albumin $(8 \%)$ concentrations. Less than $2 \%$ of animals had serum urea concentration below the optimal range $(<1.7 \mathrm{mmol} / \mathrm{L})$, and this disorder is not discussed beyond this point. A total of $23 \%$ of animals (205 cows) had 1 or more energy metabolites outside of optimal ranges. Less than 2\% (15 cows) had BHB concentrations greater than $1.2 \mathrm{mmol} / \mathrm{L}$, with a peak incidence of $20 \%(2 / 10)$ at 35 DIM. A total of $22 \%$ (199 cows) had fatty acids concentrations greater than $0.7 \mathrm{mmol} / \mathrm{L}$, with a peak incidence of $67 \%(18 / 27)$ at 8 DIM. Of the 15 hyperketonemic cows, 6 did not have a concurrent elevation in fatty acids concentrations. The prevalence of hypocalcemia and hypomagnesemia were less than 2 (15 cows) and 1\% (6 cows), respectively.

Phenotypic correlations between serum metabolite concentrations, corrected for fixed effects outlined in model 1, are shown in Table 5. Significant $(P<0.01)$ positive correlations were observed between BHB and fatty acids (0.32), $\mathrm{Ca}$ and albumin (0.39), $\mathrm{Mg}$ and albumin (0.34), urea and $\mathrm{Mg}(0.1)$, and urea and albumin (0.26). Significant negative correlations were noted between BHB and Ca $(-0.10)$, fatty acids and $\mathrm{Ca}(-0.22)$, fatty acids and urea $(-0.12)$, fatty acids and globulins $(-0.09), \mathrm{Ca}$ and globulins $(-0.11), \mathrm{Mg}$ and globulins $(-0.21)$, urea and globulins $(-0.16)$, and albumin and globulins $(-0.41)$.

\section{MIR Calibration and Validation}

The $\mathrm{R}^{2}$ and RMSE of PLS regression models investigating the relationships between blood metabolite con- centrations and MIR spectra from milk samples are shown in Table 6 . The $\mathrm{R}^{2}$ of cross-validation $\left(\mathbf{R}_{\mathbf{C V}}^{2}\right)$ and random validation $\left(\mathbf{R}_{\mathbf{R V}}^{2}\right)$ for serum BHB predictions were 0.53 and 0.48 , respectively. Predictions of serum fatty acids concentration were slightly more accurate, with an $\mathrm{R}_{\mathrm{CV}}^{2}$ of 0.56 and an $\mathrm{R}_{\mathrm{RV}}^{2}$ of 0.61 . The $\mathrm{RMSE}_{\mathrm{CV}}$ and RMSE of random validation $\left(\mathbf{R M S E} \mathbf{E}_{\mathbf{R V}}\right)$ of $\mathrm{BHB}$ and fatty acids predictions were 0.11 and 0.12 , and 0.15 and 0.14 , respectively. The most promising results were for predictions of serum urea concentration, which had $\mathrm{R}_{\mathrm{CV}}^{2}$ and $\mathrm{R}_{\mathrm{RV}}^{2}$ of $0.90, \mathrm{RMSE}_{\mathrm{CV}}$ of 0.75 , and $\mathrm{RMSE}_{\mathrm{RV}}$ of 0.82 . The accuracy of models predicting serum $\mathrm{Ca}, \mathrm{Mg}$, and globulin concentrations were poor, with $\mathrm{R}_{\mathrm{CV}}^{2}$ and $\mathrm{R}_{\mathrm{RV}}^{2}$ values less than 0.15 . The model predicting serum albumin concentration performed slightly better, with $\mathrm{R}_{\mathrm{CV}}^{2}$ of 0.23 and $\mathrm{R}_{\mathrm{RV}}^{2}$ of 0.17 .

The accuracies of prediction models when applied to the farm $\mathrm{E}$ independent validation data set (reported as $\mathbf{R}_{\text {IV }}^{2}$ and $\mathbf{R M S E}_{\mathbf{I V}}$ ) are also reported in Table 6. The $\mathrm{R}_{\mathrm{IV}}^{2}$ of $\mathrm{BHB}$ and fatty acids predictions were similar to the $\mathrm{R}_{\mathrm{CV}}^{2}$, at 0.60 and 0.45 , respectively. The $R M S E_{I V}$ of BHB and fatty acids predictions were 0.11 and 0.14 , respectively, both very close to the respective $\mathrm{RMSE}_{\mathrm{RV}}$ and $\mathrm{RMSE}_{\mathrm{CV}}$ values. The $\mathrm{R}_{\mathrm{IV}}^{2}$ for prediction of serum urea concentration however was only 0.35 , which was considerably lower than the $\mathrm{R}_{\mathrm{RV}}^{2}(0.90)$. The $\mathrm{RMSE}_{\mathrm{IV}}$ of urea prediction was $1.53 \mathrm{mmol} / \mathrm{L}$, almost double the $\mathrm{RMSE}_{\mathrm{RV}}(0.82 \mathrm{mmol} / \mathrm{L})$. The models predicting serum albumin, globulin, $\mathrm{Ca}$, and $\mathrm{Mg}$ concentrations all performed extremely poorly when applied to the independent validation data set, with $\mathrm{R}_{\mathrm{IV}}^{2}$ values between 0.00 and 0.03 .

Table 3. Mean and SD (in parentheses) of metabolite concentrations for each farm, the calibration data set, and the random validation and independent farm E validation data sets

\begin{tabular}{|c|c|c|c|c|c|c|c|c|}
\hline Data & $\mathrm{N}^{1}$ & \multicolumn{7}{|c|}{ Metabolite } \\
\hline Farm A & 315 & $0.56(0.22)$ & $0.75(0.33)$ & $2.33(0.15)$ & $0.98(0.11)$ & $5.72(1.37)$ & $33.59(2.23)$ & $39.14(5.28)$ \\
\hline Farm B & 132 & $0.49(0.19)$ & $0.31(0.21)$ & $2.32(0.12)$ & $0.96(0.12)$ & $4.94(1.52)$ & $35.13(2.05)$ & $37.07(6.22)$ \\
\hline Farm C & 147 & $0.37(0.16)$ & $0.51(0.29)$ & $2.37(0.16)$ & $0.99(0.10)$ & $2.77(0.74)$ & $32.40(2.13)$ & $40.49(5.63)$ \\
\hline Farm D & 179 & $0.66(0.24)$ & $0.26(0.14)$ & $2.33(0.13)$ & $1.02(0.10)$ & $9.00(1.23)$ & $32.69(2.41)$ & $40.00(6.44)$ \\
\hline \multicolumn{9}{|l|}{$\begin{array}{l}\text { Randomly assigned calibration } \\
\text { and validation data sets }\end{array}$} \\
\hline Calibration & 579 & $0.53(0.21)$ & $0.51(0.34)$ & $2.33(0.14)$ & $0.99(0.11)$ & $5.80(2.40)$ & $33.37(2.42)$ & $39.33(6.03)$ \\
\hline Validation & 194 & $0.54(0.29)$ & $0.53(0.34)$ & $2.34(0.14)$ & $0.98(0.11)$ & $5.75(2.50)$ & $33.55(2.34)$ & $38.98(5.48)$ \\
\hline \multicolumn{9}{|l|}{ Total } \\
\hline Data set 1 subtotal & 773 & $0.53(0.23)$ & $0.51(0.34)$ & $2.34(0.14)$ & $0.98(0.11)$ & $5.79(2.43)$ & $33.42(2.40)$ & $39.24(5.89)$ \\
\hline Independent validation data set & & & & & & & & \\
\hline Farm E & 105 & $0.56(0.26)$ & $0.29(0.26)$ & $2.43(0.13)$ & $1.10(0.10)$ & $3.75(0.78)$ & $34.60(2.30)$ & $37.18(4.87)$ \\
\hline All data & & & & & & & & \\
\hline
\end{tabular}

${ }^{1}$ Number of cows in the data set. 
The results of PLS-DA models, where affected and unaffected groups were defined using previously described metabolic profile thresholds, are shown in Table 7. Models for the prediction of elevated BHB and globulin concentrations, as well as low $\mathrm{Ca}, \mathrm{Mg}$, and albumin concentrations, were deemed to be overfitted and therefore not significant $(P>0.05)$ based on pairwise Wilcoxon signed rank permutation testing. Models for the prediction of elevated fatty acids and urea concentrations, however, were highly significant

a)

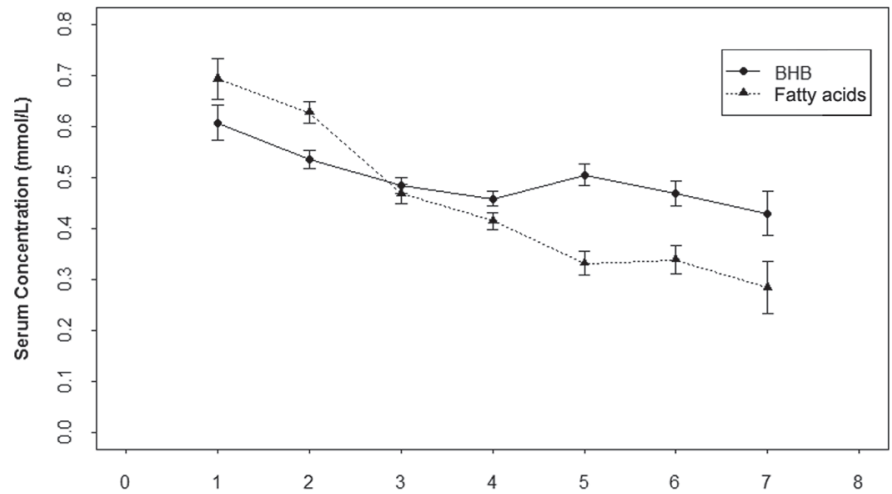

b)

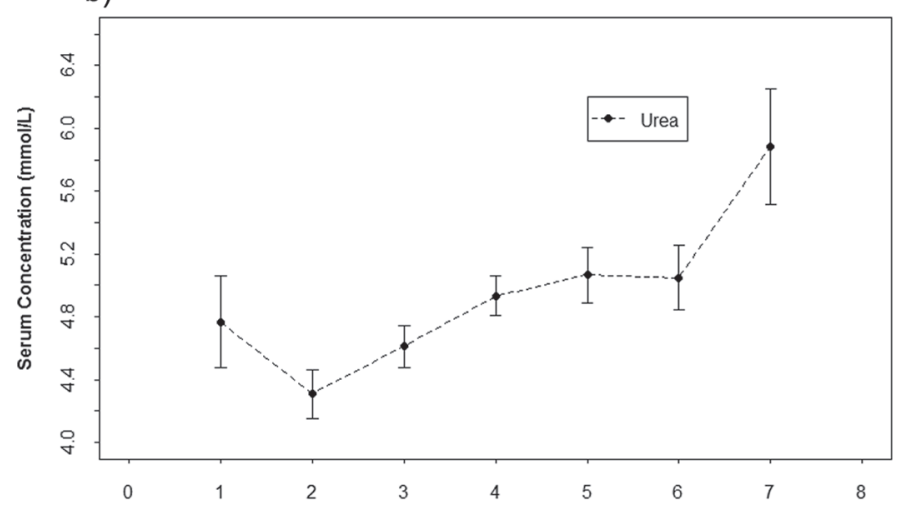

c)

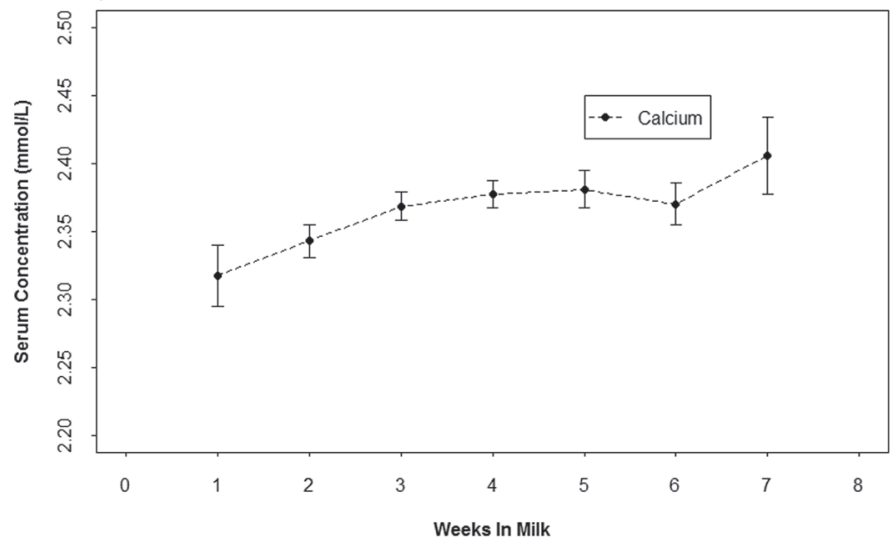

$(P<0.001)$. The sensitivity and specificity for the prediction of elevated fatty acids concentrations when applied to the random validation data set were 73 and $81 \%$, respectively, and the $\mathrm{CE}$ was $23 \%$ and the AUC was 0.87 . The MIR predicted prevalence of elevated serum fatty acids concentrations was $35 \%$. The sensitivity and specificity of the prediction of elevated urea concentrations in the random validation data set were 90 and $98 \%$, respectively, and the CE was $6 \%$ and the AUC was 0.98. The MIR-predicted prevalence

d)

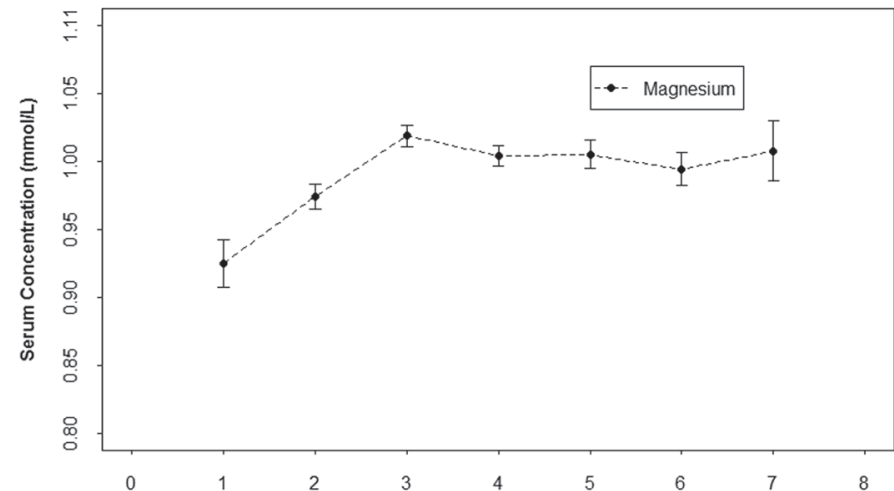

e)
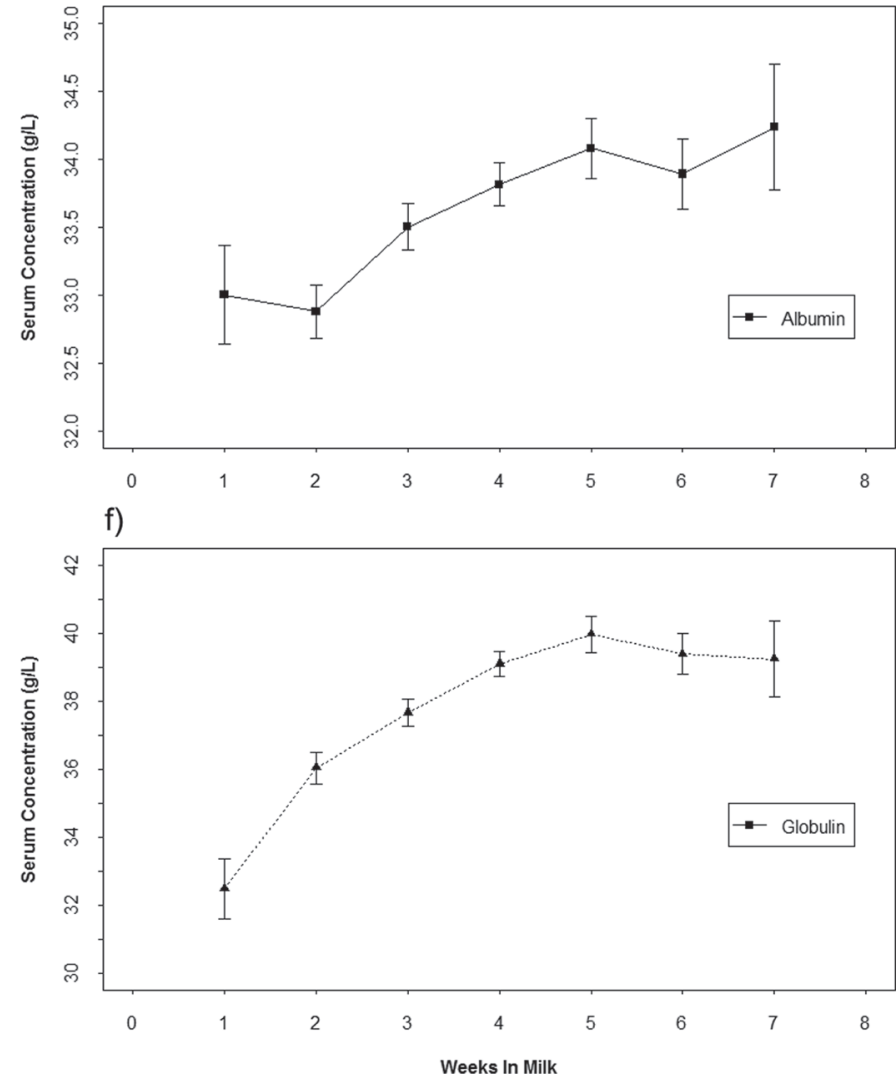

Figure 2. Estimated marginal means $( \pm \mathrm{SEM})$ of serum metabolite concentrations for each 7-d period, corrected for farm identification and parity. 
Table 4. The number and percentage (in parentheses) of animals with serum metabolite concentrations outside optimum ranges for each farm, the calibration data set, and the random validation and independent farm E validation data sets

\begin{tabular}{|c|c|c|c|c|c|c|c|c|}
\hline \multirow[b]{2}{*}{ Data } & \multirow[b]{2}{*}{$\mathrm{N}^{1}$} & \multicolumn{7}{|c|}{ Metabolite } \\
\hline & & BHB & Fatty acids & $\mathrm{Ca}$ & $\mathrm{Mg}$ & Urea & Albumin & Globulin \\
\hline \multicolumn{9}{|l|}{ Data set 1} \\
\hline Farm A & 315 & $8(3)$ & $162(51)$ & $4(1)$ & $3(1)$ & $78(25)$ & $24(8)$ & $9(3)$ \\
\hline Farm B & 132 & $1(1)$ & $5(4)$ & $4(3)$ & $2(2)$ & $18(14)$ & $2(2)$ & $4(3)$ \\
\hline Farm C & 147 & $1(1)$ & $27(18)$ & $1(1)$ & $1(1)$ & 0 & $22(15)$ & $7(5)$ \\
\hline Farm D & 179 & $3(2)$ & $1(1)$ & $4(2)$ & 0 & $175(98)$ & $21(12)$ & $8(4)$ \\
\hline Calibration & 579 & $8(1)$ & $139(24)$ & $11(2)$ & $3(1)$ & $202(35)$ & $54(9)$ & $24(4)$ \\
\hline Validation & 194 & $5(3)$ & $56(29)$ & $2(1)$ & $3(2)$ & $69(36)$ & $15(8)$ & $4(2)$ \\
\hline Data set 1 subtotal & 773 & $13(2)$ & $195(25)$ & $13(2)$ & $6(1)$ & $271(36)$ & $69(9)$ & $28(8)$ \\
\hline \multicolumn{9}{|l|}{ Independent external validation data set } \\
\hline Farm E & 105 & $2(2)$ & $4(4)$ & $2(2)$ & 0 & 0 & $4(4)$ & $1(1)$ \\
\hline \multicolumn{9}{|l|}{ All data } \\
\hline Total & 878 & $15(2)$ & $199(23)$ & $15(2)$ & $6(1)$ & $271(31)$ & $73(8)$ & $29(3)$ \\
\hline
\end{tabular}

${ }^{1}$ Number of cows in the data set.

of elevated serum urea concentrations in the random validation data set was $33 \%$.

The accuracy of PLS-DA models, when validated using the farm E independent data set, are also shown in Table 7. The sensitivity and specificity for the prediction of elevated fatty acid concentrations were 25 and $90 \%$, respectively, and the CE was $42 \%$ and the AUC was 0.82 . The MIR-predicted prevalence of elevated fatty acids in this data set was $11 \%$. The sensitivity and specificity of independent validation for the prediction of elevated urea concentrations were 100 and $89 \%$, respectively, and the $\mathrm{CE}$ was $6 \%$. The AUC could not be calculated, as no positive results (serum urea concentration $>6.8 \mathrm{mmol} / \mathrm{L}$ ) were recorded. The predicted prevalence of elevated urea concentrations was $11 \%$.

\section{DISCUSSION}

Serum concentrations of BHB, fatty acids, $\mathrm{Ca}, \mathrm{Mg}$, urea, albumin, and globulin, as measured by colorimetric methods, are routinely used to assess the metabolic health of dairy cows. Although some studies have investigated the use of MIR spectroscopy of milk to predict serum BHB and fatty acids concentrations, to the best of our knowledge this is the first study to investigate the use of MIR spectral data to predict serum concentrations of all the above metabolites. We believe this is also the first reported use of PLS-DA models to classify animals as being either affected or not affected with metabolic disorders directly from MIR spectra. Our results indicate that MIR spectral data may be a useful predictor of serum BHB, fatty acids, and urea concentrations, but not $\mathrm{Ca}, \mathrm{Mg}$, albumin, or globulin concentrations. The performance of both PLS and PLS-DA models were affected by the distribution of the calibration and validation data sets, and larger and more diverse data sets are required to improve the accuracy of predictions.

\section{Prevalence of Metabolic Disorders}

No recent studies have investigated the epidemiology of metabolic disorders in the Australian dairy herd; thus, all concentration thresholds used in ou study are based on work undertaken in New Zealand, Europe, and the United States. It should be noted that our study was not intended as an epidemiological investigation, and prevalence data are presented principally to

Table 5. Pearson correlations between serum metabolite concentrations, corrected for weeks in milk, farm identification, and parity

\begin{tabular}{lcccccc}
\hline Item & Fatty acids & $\mathrm{Ca}$ & $\mathrm{Mg}$ & Urea & Albumin & Globulin \\
\hline BHB & $0.32^{*}$ & $-0.10^{*}$ & -0.03 & 0.07 & -0.02 & -0.07 \\
Fatty acids & & $-0.22^{*}$ & -0.06 & $-0.12^{*}$ & 0.01 & $-0.09^{*}$ \\
Ca & & 0.08 & 0.08 & $0.39^{*}$ & $-0.11^{*}$ \\
$\mathrm{Mg}$ & & & $0.1^{*}$ & $0.34^{*}$ & $-0.21^{*}$ \\
Urea & & & & $0.26^{*}$ & $-0.16^{*}$ \\
Albumin & & & & & & $-0.41^{*}$ \\
\hline${ }^{*} P<0.01$ & & & & & &
\end{tabular}


Table 6. Results of partial least square regression models for the prediction of serum metabolite concentrations using milk mid-infrared spectra

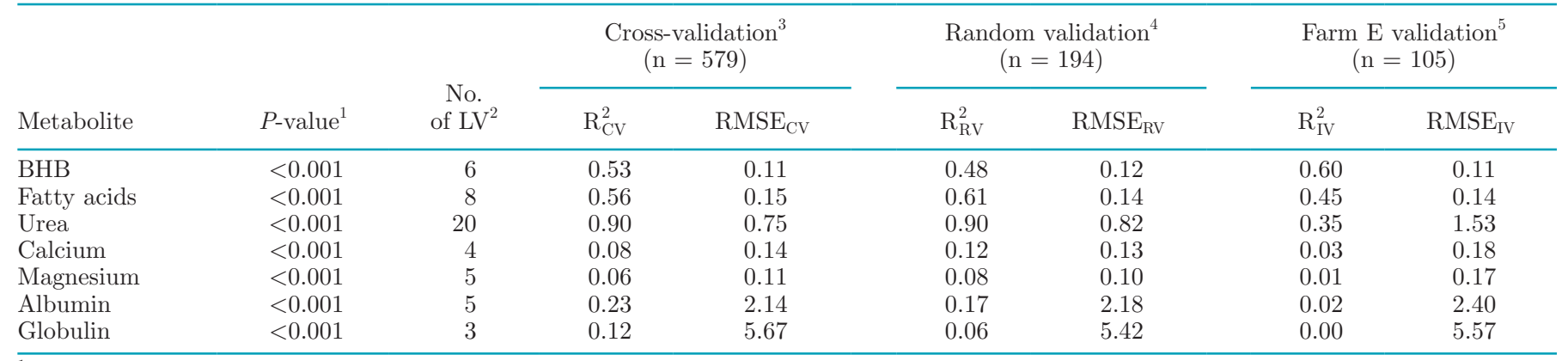

${ }^{1} P$-value for pairwise Wilcoxon signed rank test.

${ }^{2}$ Number of latent variables (LV) included in the model.

${ }^{3} \mathrm{R}_{\mathrm{CV}}^{2}=$ coefficient of determination of cross-validation; $\mathrm{RMSE}_{\mathrm{CV}}=$ root mean square error of cross-validation.

${ }^{4} \mathrm{R}_{\mathrm{RV}}^{2}=$ coefficient of determination of random external validation; $\mathrm{RMSE}_{\mathrm{RV}}=$ root mean square error of random external validation.

${ }^{5} \mathrm{R}_{\mathrm{IV}}^{2}=$ coefficient of determination of independent validation; $\mathrm{RMSE}_{\mathrm{IV}}=$ root mean square error of independent validation.

illustrate the data used to develop and validate PLSDA models.

The prevalence of hyperketonemia in our data set was $2 \%$ (15 cows), which is considerably lower than values reported in studies undertaken in New Zealand, Europe, and North America (McArt et al., 2012; Compton et al., 2014; Suthar et al., 2013). The low prevalence may have been because only approximately $4 \%$ of animals (34 cows) in our data set were in the first week of lactation, which McArt et al. (2012), demonstrated to be the period of highest hyperketonemia incidence. This was an unavoidable consequence of our study design, which involved convenience sampling on the day of routine milk recording in commercial herds. Furthermore, farmers with seasonal calving herds are often reluctant to record milk in early lactation, as it is generally a busy time of year. The timing of sampling, during or immediately after concentrate feeding, may also have affected our results, as BHB concentrations are known to vary over time, when access to feed is not constant, and to peak 4 to $5 \mathrm{~h}$ after feeding (Oetzel, 2004). All 5 farms were well-managed and implemented good transition cow management practices, which are known to minimize the incidence of ketosis. The prevalence of elevated fatty acid concentrations was 23\% (199 cows), with a peak incidence of $67 \%(18 / 27)$ at $6 \mathrm{~d}$ after calving. This was consistent with the results of Ospina et al. (2010b), who found that $65 \%$ of herds sampled had greater than $15 \%$ prevalence of elevated fatty acid concentration $(>0.70 \mathrm{mmol} / \mathrm{L})$ in cows between 3 and 14 DIM. Elevated fatty acid concentrations are arguably more significant than elevated BHB concentrations, as fatty acid concentrations have been demonstrated to be more stable over time than BHB concentrations

Table 7. Results of partial least square discriminant analysis models for the classification of serum metabolite concentrations based on metabolic profile thresholds using milk mid-infrared spectra

\begin{tabular}{|c|c|c|c|c|c|c|c|c|c|c|c|c|c|c|}
\hline \multirow[b]{2}{*}{ Metabolite } & \multirow[b]{2}{*}{$P$-value ${ }^{1}$} & \multirow[b]{2}{*}{$\mathrm{LV}^{2}$} & \multicolumn{4}{|c|}{$\begin{array}{l}\text { Cross-validation } \\
\quad(\mathrm{n}=579)\end{array}$} & \multicolumn{4}{|c|}{$\begin{array}{l}\text { Random validation } \\
\qquad(\mathrm{n}=194)\end{array}$} & \multicolumn{4}{|c|}{$\begin{array}{l}\text { Independent validation } \\
\qquad(\mathrm{n}=105)\end{array}$} \\
\hline & & & Sens ${ }^{3}$ & $\mathrm{Spec}^{4}$ & $\mathrm{CE}^{5}$ & $\mathrm{AUC}^{6}$ & Sens & Spec & $\mathrm{CE}$ & AUC & Sens & Spec & $\mathrm{CE}$ & AUC \\
\hline Fatty acids & $<0.001$ & 5 & 0.82 & 0.75 & 0.22 & 0.85 & 0.73 & 0.81 & 0.23 & 0.87 & 0.25 & 0.90 & 0.42 & 0.82 \\
\hline Urea & $<0.001$ & 20 & 0.81 & 0.91 & 0.15 & 0.94 & 0.90 & 0.98 & 0.06 & 0.98 & 1.00 & 0.89 & 0.06 & - \\
\hline Calcium & $>0.05$ & 2 & 0.36 & 0.72 & 0.46 & 0.61 & 0.00 & 0.76 & 0.62 & 0.51 & 1.00 & 0.06 & 0.47 & 0.75 \\
\hline Globulin & $>0.05$ & 5 & 0.46 & 0.73 & 0.41 & 0.63 & 0.75 & 0.76 & 0.24 & 0.87 & 1.00 & 0.42 & 0.29 & 0.99 \\
\hline
\end{tabular}

${ }^{1} P$-value for pairwise Wilcoxon signed rank test.

${ }^{2}$ Number of latent variables (LV) included in the model.

${ }^{3}$ Sensitivity.

${ }^{4}$ Specificity.

${ }^{5}$ Classification error.

${ }^{6}$ Area under the receiver operator characteristic curve. 
(Eicher et al., 1999) and have a higher association with subsequent adverse health events (Ospina et al., 2010a; Sordillo and Raphael, 2013).

A considerable percentage of animals sampled $(31 \%)$ had serum urea concentrations greater than 6.8 mmol/L, whereas less than $2 \%$ had a urea concentration less than $1.7 \mathrm{mmol} / \mathrm{L}$. These results are consistent with animals grazing rapidly growing forage with high levels of RDP (Macrae et al., 2006). Urea concentrations in serum can be used to monitor RDP intake and the ratio of RDP to energy in the ration (Roseler et al., 1993; Macrae et al., 2006). Low blood urea concentrations can indicate insufficient RDP intake, whereas high serum urea concentrations can indicate excessive RDP intake, often in the form of high protein pasture. Both insufficient and excessive RDP intake are known to limit milk production, the former due to reduced rumen microbial protein synthesis and the latter due to the significant metabolic cost of removing and detoxifying excess nitrogenous by-products from the rumen (Waghorn and Wolff, 1984; Ulyatt, 1997). Elevated serum urea concentrations before AI have also been suggested to have a negative effect on reproductive performance (Raboisson et al., 2017). Several studies have used serum urea concentrations to predict nitrogen efficiency and urinary nitrogen excretion in cattle (Kohn et al., 2005; Kume et al., 2008), which is becoming an environmental concern for the global dairy industry.

Our results indicate that metabolic disorders are prevalent in the Australian dairy herd, but further studies are required to better understand the epidemiology of early-lactation metabolic disorders. Further work is also required to determine appropriate serum metabolic profile concentration thresholds and herd-level thresholds for Australia's diverse dairy production systems.

\section{PLS Regression Models for Predicting Serum Metabolite Concentrations}

The accuracy of our MIR prediction model for serum BHB was moderate $\left(0.48 \leq \mathrm{R}^{2} \leq 0.60\right)$, which was better than those reported by Belay et al. (2017a) and similar to those reported by Smith et al. (2016) and Pralle et al. (2018). The moderate accuracy may have been in part due to the low prevalence of elevated serum BHB concentrations in our data set. The skewed distribution of the data likely resulted in lower prediction accuracy of higher BHB concentrations. Despite this, the $R_{I V}^{2}$ was higher than the $R_{C V}^{2}$ and the $R_{R V}^{2}$, suggesting that the model may be a useful indicator of ketosis risk when applied to independent data. This finding was supported by fact that the RMSE of all 3 validation methods were similar $(0.11-0.12 \mathrm{mmol} / \mathrm{L})$.
The reported accuracies of MIR predictions of milk ketone bodies are considerably higher than the accuracies of MIR serum BHB predictions (de Roos et al., 2007; Grelet et al., 2016); however, serum BHB is considered to be a superior biomarker of ketosis (Duffield et al., 1997; Denis-Robichaud et al., 2014). Whether a less-accurate predictor of the gold standard biomarker is superior to a higher accuracy predictor of a lessvaluable biomarker requires further investigation. This discussion is further complicated by the fact that, arguably, no true gold standard tests exist for many of the animal health traits being investigated (Krogh et al., 2011)

Serum fatty acid concentrations are routinely used to quantify the degree of fat mobilization, and therefore the magnitude of negative energy balance in early lactation (Ospina et al., 2010a). Few studies, however, have investigated the use of MIR of milk for predicting serum fatty acid concentrations. The $\mathrm{R}_{\mathrm{RV}}^{2}$ of our fatty acids prediction was 0.61 , which is similar to the result of Smith et al. (2016), who reported a correlation coefficient of $0.80\left(\mathrm{R}^{2}=0.64\right)$ between measured serum fatty acid concentration and MIR-predicted fatty acids concentration. McParland et al. (2011) were able to predict computed energy balance with reasonable accuracy $\left(\mathrm{R}^{2}=0.56\right)$, but they noted that their prediction equations were not robust when applied to data obtained from cows managed differently to the animals in the reference population (McParland et al., 2012). Similarly, the accuracy of our fatty acids prediction was lower when applied to the independent farm E validation data set $\left(R^{2}=0.45\right)$, but may still be a useful indicator of energy balance.

Mid-infrared is routinely used to predict MUN concentrations (Gengler et al., 2016) with good accuracy. Serum and milk urea concentrations are linearly correlated (Moore and Varga, 1996), so it follows that the MIR prediction of serum urea concentration had the highest coefficient of determination of all the metabolite models we tested. The accuracy of the urea prediction model, when applied to data from farm E, was considerably lower than when applied to the random external validation data. This may have been due to differences in the distribution of urea concentrations between the farm $\mathrm{E}$ independent data set and the reference population data set (see Table 3), as the range of data is known to have a significant effect on the $\mathrm{R}^{2}$ of PLS regression models (Davies and Fearn., 2006). Further validation with larger, more varied data sets is required to better understand these results. The MIR predictions of serum urea may be accurate enough to be a useful indicator of the protein nutrition of a herd. Large-scale predictions of serum urea concentrations could also be 
used to identify variation in nitrogen efficiency and excretion between individuals. This could be exploited in breeding programs to lower the environmental impact of dairy cattle and could also be considered as a way to increase the accuracy of genomic predictions of feed efficiency due to the high energy cost of removing excess nitrogenous by-products from the rumen. The MIR predictions of serum urea concentration could also help manage the nitrogen output of the global dairy industry, which is becoming an increasingly important environmental issue.

Mid-infrared spectroscopy has been used successfully to quantify the concentration of several milk proteins, including casein, $\alpha_{\mathrm{S} 1}-\mathrm{CN}$, whey protein, and $\beta-\mathrm{LG}$, with reasonable accuracy (De Marchi et al., 2009; Bonfatti et al., 2011; McDermott et al., 2016); however, MIR predictions of serum albumin and globulin concentrations in our study were extremely poor. Similarly, MIR spectral data has been used to estimate the $\mathrm{Ca}$ and $\mathrm{P}$ concentration of milk with reasonable accuracy (Toffanin et al., 2015); however, its ability to predict serum $\mathrm{Ca}$ and $\mathrm{Mg}$ concentrations was poor. Studies have demonstrated that animals suffering from subclinical hypocalcemia showed significant changes in their serum proteome (Wang et al., 2016; Fan et al., 2017). Given that changes in serum albumin and globulin concentrations could not be identified with milk MIR spectra, it follows that changes in serum proteome associated with hypocalcemia are also not detectable using milk MIR spectral analysis. This may suggest that changes in serum protein concentrations are not reflected in milk composition, or that a significant delay occurs between changes in serum metabolome and subsequent changes in milk composition. It should also be noted that we found considerably less variation in the concentrations of these metabolites (see Table 2) compared with the concentrations of BHB, fatty acids, and urea. As discussed previously, the distribution of data is known to have a significant effect on the accuracy of calibration models. Our results highlight the need for further work to investigate the relationships between the proteomes and metabolomes of serum and milk.

Several authors have observed that many milk MIR predictions of animal health traits are not sufficiently accurate to provide useful information on the health status of individual animals (de Roos et al., 2007; van der Drift et al., 2012; Grelet et al., 2016). These predictions may, however, be considered accurate enough to employ in genomic evaluations, as described by Bastin et al. (2016) and Bonfatti et al. (2017). The accuracy of our MIR prediction of serum BHB was better than that of Belay et al. (2017b), who used MIR predictions of serum BHB to investigate the genetic parameters of ketosis and the genetic relationships between serum BHB concentration and milk production traits. Similarly, our MIR prediction of serum fatty acids concentration had comparable accuracy to the MIR prediction of energy balance reported by McParland et al. (2015), who found favorable correlations between MIR-predicted and measured energy balance. As well as forming the basis of new traits, Pryce et al. (2016) suggested that MIR-predicted traits could be included in multitrait models to improve the accuracy of existing genomic predictions, but exactly how accurate such MIR predictions need to be to provide useful phenotypic information requires further investigation.

\section{PLS-DA for Classifying Animals Based on Metabolic Profile Testing Thresholds}

The aim of metabolic profile testing is to gain objective information on the nutritional status and metabolic health of a herd by estimating the prevalence of certain metabolic disorders. This requires a diagnostic test that can classify animals as being either affected or not affected with metabolic disorders with reasonable accuracy. The PLS-DA models are routinely used in chemometric studies to classify samples based on multivariate data. It follows, therefore, that these models may be useful for identifying cows with metabolic disorders based on their milk MIR spectra. Several authors have converted MIR predictions of continuous traits, such as BHB concentration, into binary traits based on metabolic profile thresholds (Gelé et al., 2015; Pralle et al., 2018). As far as we know, ours is the first report using PLS-DA models to classify animals directly using milk MIR spectral data. Given the poor accuracy of MIR predictions of serum $\mathrm{Ca}, \mathrm{Mg}$, albumin, and globulin concentrations, only BHB, fatty acids, and urea PLSDA models will be discussed beyond this point.

Cows that experience a serum fatty acid concentration greater than $0.7 \mathrm{mmol} / \mathrm{L}$ in the immediate postpartum period are more likely to develop clinical ketosis, metritis, or a displaced abomasum, and are more likely to be culled early than cows with normal fatty acid concentrations (McArt et al., 2013). At herd level, several authors have demonstrated that an increase in the prevalence of cows with elevated postpartum fatty acid concentrations is associated with reduced milk production and poorer fertility (Ospina et al., 2010a; Chapinal et al., 2012; McArt et al., 2013). The same authors demonstrated similar results for elevated postpartum BHB concentrations. When applied to the random validation data set, our PLS-DA model was able to predict elevated serum fatty acid concentrations $(>0.7$ $\mathrm{mmol} / \mathrm{L}$ ) with a sensitivity of $73 \%$ and a specificity of $81 \%$. Our findings are reasonably consistent with those of Gelé et al. (2015), who used a combination of BHB 
and fatty acid concentrations to identify animals at risk of subclinical ketosis with a sensitivity of $81 \%$ and a specificity of $69 \%$. The true prevalence of elevated fatty acid concentrations in our data set was $29 \%$ (95\% CI = 22.5-35.2). The MIR-predicted prevalence of elevated serum fatty acid concentrations was $35 \%$, within the $95 \%$ confidence interval of the true prevalence. When applied to the farm E validation set, the sensitivity of our fatty acids prediction decreased significantly to only $25 \%$. The MIR-predicted prevalence of elevated fatty acid concentrations in this data set was $11 \%$, which was significantly higher than the true prevalence of $4 \%$ $(95 \%$ CI $=0.1-7.5)$. This highlights the need for larger and more diverse calibration data sets to improve the accuracy of predictions before they can be used for onfarm management purposes.

Butler et al. (1996) reported that animals with a plasma urea concentration of greater than $6.8 \mathrm{mmol} / \mathrm{L}$ had lower pregnancy rates than animals with normal plasma urea concentrations. Similarly, Raboisson et al. (2017) showed a $43 \%$ lower odds of pregnancy when serum urea concentrations were above $7 \mathrm{mmol} / \mathrm{L}$, especially before AI. This may be highly relevant for the largely pasture-based Australian dairy industry, as most cows are mated in late spring at a time when they are grazing pasture high in RDP. When applied to the random validation data set, PLS-DA models could identify animals with elevated serum urea concentrations with good sensitivity (90\%) and specificity (98\%). The predicted prevalence of elevated urea concentrations was $33 \%$, close to the true prevalence of $36 \%$ (95\% $\mathrm{CI}=28.8-42.3)$. When applied to the independent farm $\mathrm{E}$ validation data set, the sensitivity of the urea prediction increased to $100 \%$ and the specificity decreased to $89 \%$. We believe these results are misleading and are artifacts of the independent validation data set being (1) relatively small, (2) having a different distribution and narrower range than the calibration data set, and (3) containing no positive results (urea concentrations $>6.8 \mathrm{mmol} / \mathrm{L})$. Given that the $\mathrm{R}_{\mathrm{IV}}^{2}$ of the PLS prediction of serum urea concentration was considerably lower than the $\mathrm{R}_{\mathrm{RV}}^{2}$ (0.35 and 0.90, respectively), we would expect the accuracy of PLS-DA predictions to be similarly lower. The MIR-predicted prevalence of elevated urea concentrations was $11 \%$, significantly higher than the true prevalence of $0 \%$. This is further evidence that a larger, more varied calibration data set is required to improve the accuracy of predictions.

The results of our PLS-DA model to predict elevated serum BHB concentrations were not significant $(P>$ $0.05)$ based on pairwise Wilcoxon rank testing of permuted samples. This was likely due to the low number of hyperketonemic samples in the data set. Lowering the threshold of BHB concentration to $1.0 \mathrm{mmol} / \mathrm{L}$ increased the statistical significance of the model. Given that the accuracy of BHB and fatty acids PLS models were similar, we would expect that the addition of more hyperketonemic samples to our data set will yield a statistically significant PLS-DA model for estimating the prevalence of subclinical ketosis.

If their accuracy can be improved, PLS-DA predictions offer a potentially useful tool to monitor the prevalence of elevated serum fatty acids, BHB, and urea concentrations. This could provide dairy producers with a valuable early warning tool that would allow them to address dietary imbalances, and thereby optimize animal health, production, and fertility.

\section{CONCLUSIONS}

We assessed the accuracy of MIR spectroscopy, performed as part of routine milk recording, for predicting the metabolic health and nutritional status of early-lactation dairy cows. We found that MIR spectroscopy of milk provided a potentially useful prediction of energy balance by reasonable estimation of serum BHB and fatty acid concentrations. The accuracy of MIR prediction of serum urea concentration was good when the validation data set had a similar range and distribution to the calibration data set. However, when the model was applied to an independent data set taken from cows of differing breeds that were managed differently, the accuracy of the prediction dropped significantly. The accuracy of MIR predictions of serum $\mathrm{Ca}, \mathrm{Mg}$, albumin, and globulin concentrations were poor. Our results demonstrate that MIR PLS-DA models may be a useful tool for estimating the prevalence of metabolic disorders in early lactation, but more data are required to improve the accuracy of prediction equations. The MIR PLS models offer potential for large-scale phenotyping that can be employed in breeding programs to breed more resilient animals with smaller environmental footprints. We aim to improve the accuracy of our prediction models by sampling more animals, particularly in the first 2 wk of lactation, thereby increasing the size and variation of our data set.

\section{ACKNOWLEDGMENTS}

We thank DairyBio, jointly funded by Dairy Australia (Melbourne, Australia) and Agriculture Victoria (Melbourne, Australia), for funding this project and T. Luke's PhD project. This work was part of a project "MIRprofit: integrating very large genomic and milk midinfrared data to improve profitability of dairy cows," supported by funding from the Australian Gov- 
ernment Department of Agriculture (Canberra, Australia) as part of the Rural R\&D for Profit programme. The authors also thank Di Mapleson, Brigid Ribaux, and the staff at Ellinbank Dairy Research Centre (Ellinbank, Australia) for their technical expertise and assistance, Erika Oakes and Michelle Axford of Datagene (Bundoora, Australia) for their work coordinating this study, and the farmers who took part in this project.

\section{REFERENCES}

Anderson, D. E. 2009. Current Veterinary Therapy: Food Animal Practice. Saunders Elsevier, St. Louis, MO.

Afseth, N. K., H. Martens, A. Randby, L. Gidskehaug, B. Narum, K. Jorgensen, S. Lien, and A. Kohler. 2010. Predicting the fatty acid composition of milk: A comparison of two Fourier transform infrared sampling techniques. Appl. Spectrosc. 64:700-707. https://doi org $/ 10.1366 / 000370210791666200$

Bastin, C., L. Théron, A. Lainé, and N. Gengler. 2016. On the role of mid-infrared predicted phenotypes in fertility and health dairy breeding programs. J. Dairy Sci. 99:4080-4094. https://doi.org/10 .3168/jds.2015-10087.

Belay, T. K., B. S. Dagnachew, Z. M. Kowalski, and T. Ådnøy. 2017a. An attempt at predicting blood $\beta$-hydroxybutyrate from Fouriertransform mid-infrared spectra of milk using multivariate mixed models in Polish dairy cattle. J. Dairy Sci. 100:6312-6326. https:/ /doi.org/10.3168/jds.2016-12252.

Belay, T. K., M. Svendsen, Z. M. Kowalski, and T. Ådnøy. 2017b. Genetic parameters of blood $\beta$-hydroxybutyrate predicted from milk infrared spectra and clinical ketosis, and their associations with milk production traits in Norwegian Red cows. J. Dairy Sci. 100:6298-6311. https://doi.org/10.3168/jds.2016-12458.

Bonfatti, V., G. Di Martino, and P. Carnier. 2011. Effectiveness of mid-infrared spectroscopy for the prediction of detailed protein composition and contents of protein genetic variants of individual milk of Simmental cows. J. Dairy Sci. 94:5776-5785. https://doi .org/10.3168/jds.2011-4401.

Bonfatti, V., D. Vicario, A. Lugo, and P. Carnier. 2017. Genetic parameters of measures and population-wide infrared predictions of 92 traits describing the fine composition and technological properties of milk in Italian Simmental cattle. J. Dairy Sci. 100:55265540. https://doi.org/10.3168/jds.2016-11667.

Butler, W. R., J. J. Calaman, and S. W. Beam. 1996. Plasma and milk urea nitrogen in relation to pregnancy rate in lactating dairy cattle. J. Anim. Sci. 74:858-865.

Chapinal, N., S. J. Leblanc, M. E. Carson, K. E. Leslie, S. Godden, M. Capel, J. E. Santos, M. W. Overton, and T. F. Duffield. 2012. Herd-level association of serum metabolites in the transition period with disease, milk production, and early lactation reproductive performance. J. Dairy Sci. 95:5676-5682. https://doi.org/10 $.3168 /$ jds.2011-5132.

Compton, C. W., S. McDougall, L. Young, and M. Bryan. 2014. Prevalence of subclinical ketosis in mainly pasture-grazed dairy cows in New Zealand in early lactation. N. Z. Vet. J. 62:30-37. https://doi .org/10.1080/00480169.2013.823829.

Compton, C. W., L. Young, and S. McDougall. 2015. Subclinical ketosis in post-partum dairy cows fed a predominantly pasture-based diet: defining cut-points for diagnosis using concentrations of betahydroxybutyrate in blood and determining prevalence. N. Z. Vet. J. 63:241-248. https://doi.org/10.1080/00480169.2014.999841.

Davies, A., and T. Fearn. 2006. Back to basics: Calibration statistics. Spectroscopy Europe 18:31-32.

De Marchi, M., V. Bonfatti, A. Cecchinato, G. Di Martino, and P. Carnier. 2009. Prediction of protein composition of individual cow milk using mid-infrared spectroscopy. Ital. J. Anim. Sci. 8:399 401. https://doi.org/10.4081/ijas.2009.s2.399.

de Roos, A. P. W., H. J. C. M. van Den Bijgaart, J. Hørlyk, and G. de Jong. 2007. Screening for subclinical ketosis in dairy cattle by fou- rier transform infrared spectrometry. J. Dairy Sci. 90:1761-1766. https://doi.org/10.3168/jds.2006-203.

DeGaris, P. J., and I. J. Lean. 2008. Milk fever in dairy cows: A review of pathophysiology and control principles. Vet. J. 176:58-69. https: //doi.org/10.1016/j.tvjl.2007.12.029.

Denis-Robichaud, J., J. Dubuc, D. Lefebvre, and L. Descôteaux. 2014 Accuracy of milk ketone bodies from flow-injection analysis for the diagnosis of hyperketonemia in dairy cows. J. Dairy Sci. 97:33643370. https://doi.org/10.3168/jds.2013-6744

Duffield, T. F., D. F. Kelton, K. E. Leslie, K. D. Lissemore, and J. H. Lumsden. 1997. Use of test day milk fat and milk protein to detect subclinical ketosis in dairy cattle in Ontario. Can. Vet. J. 38:713.

Eicher, R., A. Liesegang, E. Bouchard, and A. Tremblay. 1999. Effect of cow-specific factors and feeding frequency of concentrate on diurnal variations of blood metabolites in dairy cows. Am. J. Vet. Res. 60:1493-1499.

Eigenvector. 2018. PLS Toolbox User Guide. Vol. 2018. Eignevector Research Inc., Manson, WA

Fan, Z., S. Shu, C. Xu, X. Xiao, G. Wang, Y. Bai, C. Xia, L. Wu, H. Zhang, C. Xu, and W. Yang. 2017. Protein profiling of plasma proteins in dairy cows with subclinical hypocalcaemia. Ir. Vet. J. 70:3. https://doi.org/10.1186/s13620-017-0082-0.

Gelé, M., M. Ferrand-Calmels, L. Brun-Lafleur, A. Werner, and F. Gollé-Leidreiter. 2015. Predicting the risk of ketosis using mid infrared spectrometry. Pages 19-24 in Proceedings of ICAR Technical Series. International Committee for Animal Recording (ICAR), Rome, Italy.

Gengler, N., H. Soyeurt, F. Dehareng, C. Bastin, F. Colinet, H. Hammami, M. L. Vanrobays, A. Lainé, S. Vanderick, C. Grelet, A. Vanlierde, E. Froidmont, and P. Dardenne. 2016. Capitalizing on fine milk composition for breeding and management of dairy cows. J. Dairy Sci. 99:4071-4079. https://doi.org/10.3168/jds.2015-10140.

Grelet, C., C. Bastin, M. Gelé, J. B. Davière, M. Johan, A. Werner, R. Reding, J. A. Fernandez Pierna, F. G. Colinet, P. Dardenne, N. Gengler, H. Soyeurt, and F. Dehareng. 2016. Development of Fourier transform mid-infrared calibrations to predict acetone, $\beta$-hydroxybutyrate, and citrate contents in bovine milk through a European dairy network. J. Dairy Sci. 99:4816-4825. https://doi .org/10.3168/jds.2015-10477.

Hamann, J., and V. Krömker. 1997. Potential of specific milk composition variables for cow health management. Livest. Prod. Sci. 48:201-208. https://doi.org/10.1016/S0301-6226(97)00027-4.

Jonker, J. S., R. A. Kohn, and J. High. 2002. Use of milk urea nitrogen to improve dairy cow diets. J. Dairy Sci. 85:939-946. https://doi .org/10.3168/jds.S0022-0302(02)74152-0.

Kohn, R. A., M. M. Dinneen, and E. Russek-Cohen. 2005. Using blood urea nitrogen to predict nitrogen excretion and efficiency of nitrogen utilization in cattle, sheep, goats, horses, pigs, and rats. J. Anim. Sci. 83:879. https://doi.org/10.2527/2005.834879x.

Krogh, M. A., N. Toft, and C. Enevoldsen. 2011. Latent class evaluation of a milk test, a urine test, and the fat-to-protein percentage ratio in milk to diagnose ketosis in dairy cows. J. Dairy Sci. 94:2360-2367. https://doi.org/10.3168/jds.2010-3816.

Kume, S., K. Numata, Y. Takeya, Y. Miyagawa, S. Ikeda, M. Kitagawa, K. Nonaka, T. Oshita, and T. Kozakai. 2008. Evaluation of urinary nitrogen excretion from plasma urea nitrogen in dry and lactating cows. (Report). Asian-Australas. J. Anim. Sci. 21:1159. https://doi.org/10.5713/ajas.2008.70734.

LeBlanc, S. J., K. D. Lissemore, D. F. Kelton, T. F. Duffield, and K. E. Leslie. 2006. Major advances in disease prevention in dairy cattle. J. Dairy Sci. 89:1267-1279. https://doi.org/10.3168/jds.S0022 $-0302(06) 72195-6$.

Macrae, A. I., D. A. Whitaker, E. Burrough, A. Dowell, and J. M. Kelly. 2006. Use of metabolic profiles for the assessment of dietary adequacy in UK dairy herds. Vet. Rec. 159:655. https://doi.org/ $10.1136 / v r .159 .20 .655$.

McArt, J. A. A., D. V. Nydam, and G. R. Oetzel. 2012. Epidemiology of subclinical ketosis in early lactation dairy cattle. J. Dairy Sci. 95:5056-5066. https://doi.org/10.3168/jds.2012-5443.

McArt, J. A. A., D. V. Nydam, G. R. Oetzel, T. R. Overton, and P. A. Ospina. 2013. Elevated non-esterified fatty acids and 
$\beta$-hydroxybutyrate and their association with transition dairy cow performance. Vet. J. 198:560. https://doi.org/10.1016/j.tvjl.2013 .08 .011

McArt, J. A. A., D. V. Nydam, and M. W. Overton. 2015. Hyperketonemia in early lactation dairy cattle: A deterministic estimate of component and total cost per case. J. Dairy Sci. 98:2043-2054. https://doi.org/10.3168/jds.2014-8740.

McDermott, A., G. Visentin, M. De Marchi, D. P. Berry, M. A. Fenelon, P. M. O'connor, O. A. Kenny, and S. McParland. 2016. Prediction of individual milk proteins including free amino acids in bovine milk using mid-infrared spectroscopy and their correlations with milk processing characteristics. J. Dairy Sci. 99:3171-3182. https://doi.org/10.3168/jds.2015-9747.

McParland, S., G. Banos, B. McCarthy, E. Lewis, M. P. Coffey, B. O'neill, M. O'donovan, E. Wall, and D. P. Berry. 2012. Validation of mid-infrared spectrometry in milk for predicting body energy status in Holstein-Friesian cows. J. Dairy Sci. 95:7225-7235. https: //doi.org/10.3168/jds.2012-5406.

McParland, S., G. Banos, E. Wall, M. P. Coffey, H. Soyeurt, R. F. Veerkamp, and D. P. Berry. 2011. The use of mid-infrared spectrometry to predict body energy status of Holstein cows. J. Dairy Sci. 94:3651-3661. https://doi.org/10.3168/jds.2010-3965.

McParland, S., E. Kennedy, E. Lewis, S. G. Moore, B. McCarthy, M. O'donovan, and D. P. Berry. 2015. Genetic parameters of dairy cow energy intake and body energy status predicted using midinfrared spectrometry of milk. J. Dairy Sci. 98:1310-1320. https:/ /doi.org/10.3168/jds.2014-8892.

Moore, D. A., and G. Varga. 1996. BUN and MUN: Urea nitrogen testing in dairy cattle. Compend. Contin. Educ. Pract. Vet. 18:712720

National Health and Medical Research Council. 2013. Australian Code for the Care and Use of Animals for Scientific Purposes. 8th ed. National Health and Medical Research Council, Canberra, Australia.

Nousiainen, J., K. J. Shingfield, and P. Huhtanen. 2004. Evaluation of milk urea nitrogen as a diagnostic of protein feeding. J. Dairy Sci. 87:386-398. https://doi.org/10.3168/jds.S0022-0302(04)73178-1.

Oetzel, G. R. 2004. Monitoring and testing dairy herds for metabolic disease. Vet. Clin. North Am. Food Anim. Pract. 20:651-674. https://doi.org/10.1016/j.cvfa.2004.06.006.

Ospina, P. A., D. Nydam, T. Stokol, and T. Overton. 2010a. Associations of elevated nonesterified fatty acids and [beta]-hydroxybutyrate concentrations with early lactation reproductive performance and milk production in transition dairy cattle in the northeastern United States. J. Dairy Sci. 93:1596-1603.

Ospina, P. A., D. V. Nydam, T. Stokol, and T. R. Overton. 2010b. Association between the proportion of sampled transition cows with increased nonesterified fatty acids and beta-hydroxybutyrate and disease incidence, pregnancy rate, and milk production at the herd level. J. Dairy Sci. 93:3595-3601. https://doi.org/10.3168/ jds.2010-3074.

Paudyal, S., F. P. Maunsell, C. A. Risco, A. Donovan, A. D. Vries, D. Manriquez, and P. J. Pinedo. 2016. Evaluating milk fat to protein ratio and milk fat to lactose ratio as indicators for early lactation disease. J. Anim. Sci. 94:69. (Abstr.)

Payne, J. M., S. M. Dew, R. Manston, and M. Faulks. 1970. The use of a metabolic profile test in dairy herds. Vet. Rec. 87:150. https:/ /doi.org/10.1136/vr.87.6.150.

Pralle, R. S., K. W. Weigel, and H. M. White. 2018. Predicting blood $\beta$-hydroxybutyrate using milk Fourier transform infrared spectrum, milk composition, and producer-reported variables with multiple linear regression, partial least squares regression, and artificial neural network. J. Dairy Sci. 101:4378-4387. https://doi .org/10.3168/jds.2017-14076.

Pryce, J. E., K. L. Parker Gaddis, A. Koeck, C. Bastin, M. Abdelsayed, N. Gengler, F. Miglior, B. Heringstad, C. Egger-Danner,
K. F. Stock, A. J. Bradley, and J. B. Cole. 2016. Invited review: Opportunities for genetic improvement of metabolic diseases. J. Dairy Sci. 99:6855-6873. https://doi.org/10.3168/jds.2016-10854.

Raboisson, D., A. Albaaj, G. Nonne, and G. Foucras. 2017. High urea and pregnancy or conception in dairy cows: A meta-analysis to define the appropriate urea threshold. J. Dairy Sci. 100:7581. (Abstr.) https://doi.org/10.3168/jds.2016-12009.

Roseler, D. K., J. D. Ferguson, C. J. Sniffen, and J. Herrema. 1993. Dietary protein degradability effects on plasma and milk urea nitrogen and milk nonprotein nitrogen in Holstein cows. J. Dairy Sci 76:525-534. https://doi.org/10.3168/jds.S0022-0302(93)77372-5.

Schcolnik, T. 2016. Using milk fat-to-protein ratio to evaluate dairy cows energy balance status. J. Anim. Sci. 94:54. (Abstr.)

Smith, S., V. Hicks, R. Cooper, J. Forrest, A. Macrae, and E. Wall. 2016. Developing a bovine ketosis risk indicator using spectral and phenotypic data. Page 301 in Proc. 67th Annu. Meeting of EAAP, Belfast, UK. Wageningen Academic Publishers, Wageningen, the Netherlands.

Sordillo, L. M., and W. Raphael. 2013. Significance of metabolic stress, lipid mobilization, and inflammation on transition cow disorders. Vet. Clin. North Am. Food Anim. Pract. 29:267-278. https://doi .org/10.1016/j.cvfa.2013.03.002.

Suthar, V. S., J. Canelas-Raposo, A. Deniz, and W. Heuwieser. 2013. Prevalence of subclinical ketosis and relationships with postpartum diseases in European dairy cows. J. Dairy Sci. 96:2925-2938. https://doi.org/10.3168/jds.2012-6035.

Toffanin, V., M. De Marchi, N. Lopez-Villalobos, and M. Cassandro. 2015. Effectiveness of mid-infrared spectroscopy for prediction of the contents of calcium and phosphorus, and titratable acidity of milk and their relationship with milk quality and coagulation properties. Int. Dairy J. 41:68-73. https://doi.org/10.1016/j .idairyj.2014.10.002.

Toni, F., L. Vincenti, L. Grigoletto, A. Ricci, and Y. H. Schukken. 2011. Early lactation ratio of fat and protein percentage in milk is associated with health, milk production, and survival. J. Dairy Sci. 94:1772-1783. https://doi.org/10.3168/jds.2010-3389.

Ulyatt, M. J. 1997. Can protein utilisation from pasture be improved? Pages 4-8 in Proc. NZ Soc. of Anim. Prod. Annu. Meeting, Palmerston North, New Zealand. N. Z. Soc. Anim. Prod., Wellington, New Zealand.

van der Drift, S. G. A., R. Jorritsma, J. T. Schonewille, H. M. Knijn, and J. A. Stegeman. 2012. Routine detection of hyperketonemia in dairy cows using Fourier transform infrared spectroscopy analysis of $\beta$-hydroxybutyrate and acetone in milk in combination with test-day information. J. Dairy Sci. 95:4886-4898. https://doi.org/ 10.3168/jds.2011-4417.

van Knegsel, A. T. M., S. G. A. van Der Drift, M. Horneman, A. P. W. de Roos, B. Kemp, and E. A. M. Graat. 2010. Short communication: Ketone body concentration in milk determined by Fourier transform infrared spectroscopy: Value for the detection of hyperketonemia in dairy cows. J. Dairy Sci. 93:3065-3069. https://doi .org/10.3168/jds.2009-2847.

Waghorn, G. C., and J. E. Wolff. 1984. Theoretical considerations for partitioning nutrients between muscle and adipose tissue. Pages 193-200 in Proc. NZ Soc. of Anim. Prod. Annu. Meeting. N. Z. Soc. Anim. Prod., Wellington, New Zealand.

Wang, P. X., S. Shu, C. Xia, Z. Wang, L. Wu, B. Wang, C. C. Xu, and J. Liu. 2016. Protein expression in dairy cows with and without subclinical hypocalcaemia. N. Z. Vet. J. 64:101-106. https://doi .org/10.1080/00480169.2015.1100970.

Whitaker, D. A. 2004. Metabolic profiles. Pages 804-817 in Bovine Medicine: Diseases and Husbandry of Cattle. 2nd ed. Blackwell Science, Oxford, UK. 